\title{
Correction to: Effluent composition prediction of a two-stage anaerobic digestion process: machine learning and stoichiometry techniques
}

\author{
Luz Alejo $^{1} \cdot$ John Atkinson $^{2} \cdot$ Constanza Arriagada $^{1} \cdot$ Víctor Guzmán-Fierro $^{1} \cdot$ Marlene Roeckel $^{1}$
}

Published online: 7 January 2019

(C) Springer-Verlag GmbH Germany, part of Springer Nature 2019

\section{Correction to: Environmental Science and Pollution Research (2018) 25:21149-21163 \\ https://doi.org/10.1007/s11356-018-2224-7}

The original publication of this paper contains a mistake. Unfortunately, an author was inadvertently missed out, Constanza Arriagada had participated in the operation of the anaerobic digesters cited in the work and now as a $\mathrm{PhD}$ student, she is involved in the production of other publication that comprise some results of the experiments published in the article we wrote.

Publisher's Note Springer Nature remains neutral with regard to jurisdictional claims in published maps and institutional affiliations.

The online version of the original article can be found at https://doi.org/ $10.1007 / \mathrm{s} 11356-018-2224-7$

Marlene Roeckel

mroeckel@udec.cl

John Atkinson

john.atkinson@uai.cl

1 Departamento de Ingeniería Química, Universidad de Concepción, Víctor Lamas 1290, Casilla 160-C Correo 3, Concepción, Chile

2 Facultad de Ingeniería y Ciencias, Universidad Adolfo Ibáñez, Santiago, Chile 